\title{
Prospective Evaluation of Spino-Pelvic Parameters with Clinical Correlation in Patients Operated with an Anterior Lumbar Interbody Fusion
}

\author{
Stanislas Marouby, Remy Coulomb, Etienne Maury, Chahine Assi, Olivier Mares, Pascal Kouyoumdjian \\ Department of Orthopedic Surgery, Caremeau University Hospital, Nimes, France
}

\begin{abstract}
Study Design: Prospective study.
Purpose: The goal of this study was to evaluate the impact of anterior lumbar interbody fusion (ALIF) on L5-S1 level for restitution of distal segmental lordosis and to investigate its consequences on spino-pelvic parameters and the global sagittal balance.

Overview of Literature: Lumbar surgery must be adapted to the spinal morphology in order to restore an adequate relation between pelvic and spinal parameters and especially to the pelvic incidence.

Methods: An observational, prospective study was conducted between January 2013 and May 2017. Eighty-six patients were treated by L5-S1 ALIF procedure regardless of disc replacement above L5-S1 level. Thirty-seven patients were included and subset analyses were performed on 25 patients operated on an isolated ALIF L5-S1 (group 1), and 12 patients with hybrid surgery consisting of an L5S1 ALIF procedure and a L4-L5 lumbar disc replacement (group 2). Clinical parameters were analyzed using Visual Analog Scale (VAS) and Oswestry Disability Index (ODI) at M0 (preoperative) and M12 (12 months). Lumbo-pelvic parameters were assessed on a standing full-spine $\mathrm{X}$-ray, preoperatively and at M12 after surgery.

Results: We observed a significant evolution of L1-S1 lumbar lordosis $(p<0.001)$ with a significant increase of the distal arch L4-S1 lordosis $(p<0.001)$ and decrease of the proximal arch lordosis $(p=0.03)$. Preoperatively, $27 \%$ of the patients were unbalanced. Significant variation in sagittal balance parameters was observed, with a decrease of the sagittal vertebral axis $(p<0.001)$. VAS and ODI improved significantly but no correlation was found. An evolution in the same direction was found in the two subgroup analyses. Conclusions: ALIF procedure on L5-S1 level allowed a reconstruction of lumbosacral segmental lordosis, modification of global lordosis, without variation of spino-pelvic parameters except an improvement in sagittal balance.
\end{abstract}

Keywords: Anterior lumbar interbody fusion; Lumbar disc replacement; Pelvic parameters; Sagittal balance; Segmental lordosis

\section{Introduction}

Sagittal balance is a critical aspect in the management of lumbar degenerative disc diseases and its restoration remains a big challenge. An ergonomic posture necessi- tates adequate coordination between the pelvic and spinal parameters [1-3]. Sagittal balance is restored through changes that occur in spino-pelvic parameters including increase in upper lumbar lordosis (LL), decrease in sacral slope (SS), reduction in thoracic kyphosis (TK) and knee

Received Feb 5, 2019; Revised Apr 1, 2019; Accepted May 3, 2019

Corresponding author: Stanislas Marouby

Department of Orthopedic Surgery, Caremeau University Hospital, Place du Professeur Robert Debré, 30029 Nimes, France

Tel: +33-4666831, Fax: +33-466684304, E-mail: Stanislasmrb@gmail.com 
flessum [1]. The L4-S1 segment contributes to two-thirds of the LL value and in a major way, represents the adaptability of the lumbo-pelvic complex in sitting and standing postures $[1,4]$. The loss of lordosis of the distal arch results in a reduction in disc height at level L4-S1 causing structural damage in distal lumbar degenerative disc disease. As well, isolated distal lumbar discopathy, with loss of disc height, can induce segmental lumbo-pelvic kyphosis $[3,5,6]$. One- or two-level anterior or lateral lumbar interbody fusions can alter segmental LL with or without modification of the lumbo-pelvic kinematic parameters [7]; however, whether this modification can be applied to the preoperative status is not clear.

The aim of this study was to evaluate the impact of isolated anterior lumbosacral fusion on segmental lordosis (SL) of L5-S1 and its influence on lumbo-pelvic parameters. We hypothesize that anterior lumbar interbody fusion (ALIF) modifies these parameters especially in sagittal unbalanced patients.

\section{Materials and Methods}

\section{Population description}

This was a prospective study comprising 86 consecutive patients who underwent L5-S1 ALIF procedure for lumbo-pelvic discopathy between January 2013 and May 2017. Patients who met all the inclusion criteria-chronic low back pain in relation to an active discopathy with Modic 1 [7] or Pfirrmann 5 [8] signal on the magnetic resonance imaging (MRI), and degenerative lesion of the
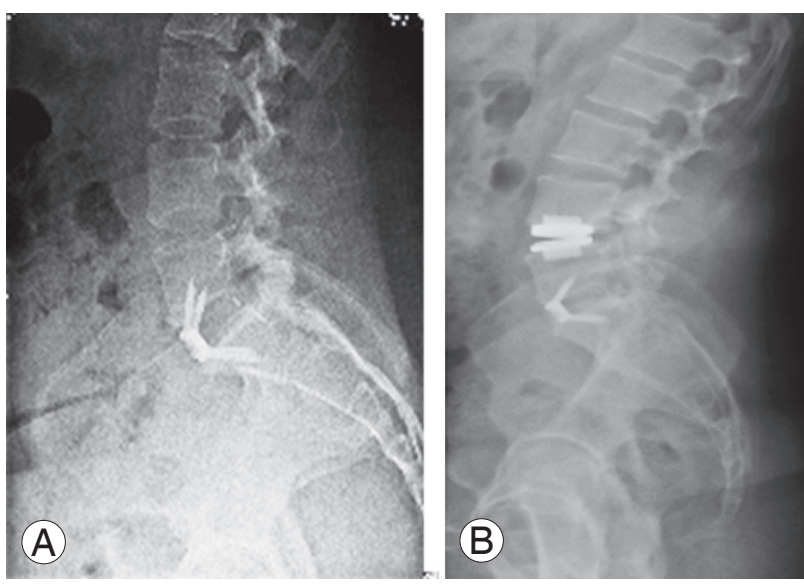

Fig. 1. (A, B) Lateral X-ray of isolated L5-S1 ALIF procedure (group 1) and hybrid surgery: L5-S1 ALIF procedure and L4-L5 lumbar disc replacement (group 2). ALIF, anterior lumbar interbody fusion. articular process at the L5-S1 level without arthritis at L4-L5 level-were assigned to two groups. Group 1 (G1) consisted of patients who with isolated L5-S1 level or hybrid surgery (L5-S1 ALIF procedure associated with L4L5 lumbar disc replacement (LDR), and group 2 (G2) for symptomatic lumbar degenerative disc disease (one or two level) (Fig. 1). Patients were excluded from this study if they had (1) history of instrumented spinal surgery; (2) deformity and spondylolisthesis; (3) traumatic spine or spinal infections; (4) multi-level disc diseases (more than 3); (5) no L5-S1 fusion on computed tomography (CT)scan according to Lenke's criteria (retained patients had a Lenke score of 1) [9] and criteria of Surgical Interbody Research Group [10]); and (6) L4-L5 arthroplasty fused, incomplete files.

\section{Clinical evaluation}

Patients were prospectively evaluated (preoperatively and at 12 months) by the lumbar Visual Analog Scale (VAS)score to quantify the intensity of low back pain, VAS-score for leg pain and Oswestry Disability Index (ODI).

\section{Analysis of X-rays and lumbo-pelvic parameters}

Measurements of spino-pelvic parameters were performed preoperatively and postoperatively at 12 months after surgery on a standing full-spine X-ray using the KEOPS software (SMAIO, Lyon, France) (Fig. 2). Assessment of pelvic incidence (PI), pelvic tilt (PT), SS, and Roussouly's classification according to SS were performed [11,12].

Two different methods were used to measure global lumbar lordosis (GLL): (1) by the angle between the tangents to the superior endplate of L1 and inferior endplate of S1 and (2) by the Cobb technique between the tangent to the S1 endplate and the tangent to the upper endplate of the most inclined vertebra at the thoraco-lumbar junction.

Different sections of the LL with the segmental lumbar lordosis (LLS) were collected; the proximal LL arc (above L4) between L1-L4, distal LL arc (below L4) between L4-S1, L5-S1, L4-L5 and the TK measured by the Cobb technique between the two inflection points. Sagittal morphotype of each patient was collected according to Roussouly's classification.

Sagittal balance parameters analyzed were: the spinosacral angle (SSA), sagittal vertical axis (SVA), C7 sagittal lodge, and the C7 Barrey-ratio (C7 BR) as defined by Bar- 
rey et al. [1,2]. Fusion status was assessed on standing radiographs and CT scans at 12 months using Lenke's classification [9] and criteria of Surgical Interbody Research Group [10].

\section{Sagittal kinematics parameters}

Patients were categorized as [13-15]:

1) Unbalanced, if they presented at least one of these cri-
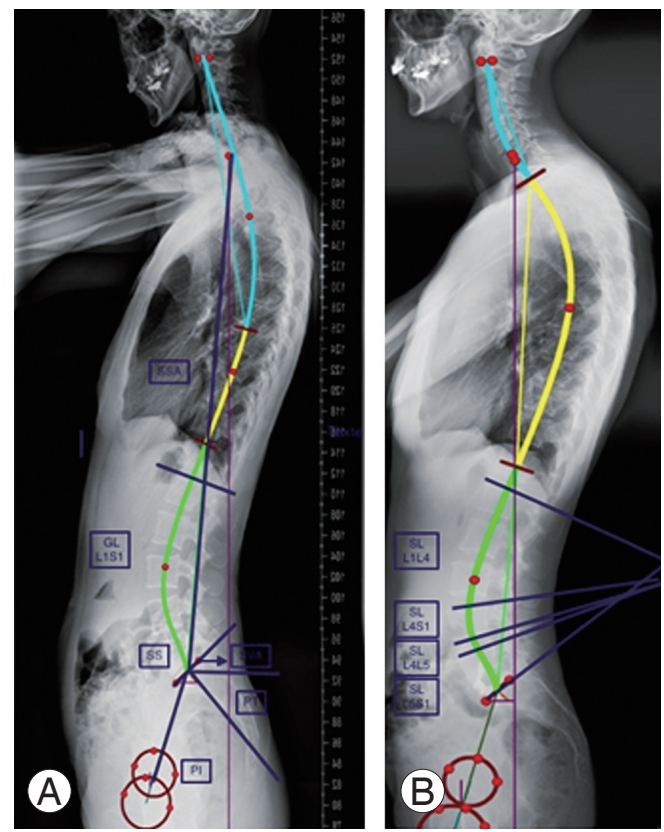

Fig. 2. (A, B) Measurement of spino-pelvic parameters via optispine software KEOPS (SMAIO, Lyon, France). teria: SVA distance greater than $50 \mathrm{~mm}, \mathrm{C} 7 \mathrm{BR}>100 \%$.

2) Balanced with abnormal kinematics lumbo-pelvic parameters resulting from the use of compensatory mecha-

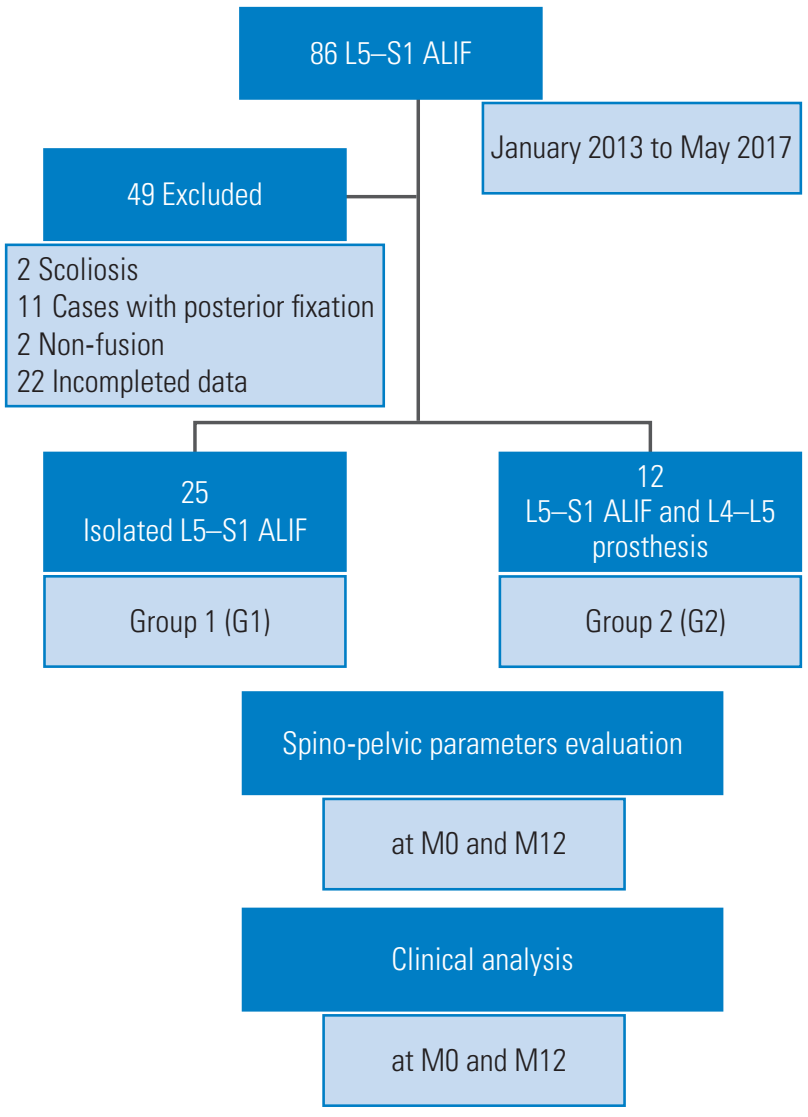

Fig. 3. Flow-chart. ALIF, anterior lumbar interbody fusion.

Table 1. Demographic data

\begin{tabular}{|c|c|c|c|c|}
\hline Characteristic & Global & Group 1 & Group 2 & $\begin{array}{c}p \text {-value } \\
\text { Igroup } 1 \text { vs. group } 2\end{array}$ \\
\hline No. of patients & 37 & 25 & 12 & \\
\hline Age (yr) & $45.8 \pm 8.7(26-63)$ & $47.8 \pm 9.1(26-53)$ & $41.6 \pm 6.5(30-63)$ & 0.04 \\
\hline Gender & & & & 0.69 \\
\hline Female & 23 & 15 & 8 & \\
\hline Male & 14 & 10 & 4 & \\
\hline Body mass index $\left(\mathrm{kg} / \mathrm{m}^{2}\right)$ & $24.7 \pm 4.8(16.6-37.3)$ & $25.8 \pm 5.0(16.6-28)$ & $22.2 \pm 3.4(17-37.3)$ & 0.01 \\
\hline American Society of Anesthesiologists score & $1.5 \pm 0.6(1-3)$ & $1.5 \pm 0.5(1-3)$ & $1.5 \pm 0.6(1-3)$ & 0.91 \\
\hline \multicolumn{5}{|l|}{ Implants } \\
\hline RoiA LDR & 5 & 5 & 0 & \\
\hline Synfix (synthes) & 32 & 20 & 12 & \\
\hline Lordosis $\left({ }^{\circ}\right)$ & $10.8 \pm 1.8(8-14)$ & $10.9 \pm 1.9(8-12)$ & $10.7 \pm 1.8(8-14)$ & 0.66 \\
\hline Height (mm) & $12.4 \pm 1.0(10-15)$ & $12.6 \pm 0.8(10-15)$ & $12.0 \pm 1.4(12-14)$ & 0.56 \\
\hline
\end{tabular}

Values are presented as mean \pm standard deviation (min-max) or number. 
nism [16], $\mathrm{PT}>20^{\circ}$, hypo-TK $<30^{\circ}$.

3) Balanced, no criteria of imbalance or compensatory mechanisms.

\section{Surgical technique}

All patients underwent surgeries performed by the same senior surgeon. After patients lay in the "supine split-leg" position, a midline laparotomy incision (in case of two level surgery L4-L5 and L5-S1) or right hemi-Pfannenstiel (in case of L5-S1 isolated fusion) was performed by the retroperitoneal approach. The right side was chosen for isolated L5-S1 ALIF procedure and the left side in cases of two level surgeries. While a standard discectomy was performed in all cases, the posterior longitudinal ligament release was performed only in case of radicular pain associated with protrusion of the intervertebral disc. Two types of implants were used for the ALIF procedure: LDR lab ROI A (Roi-A, ALIF, Zimmer Biomet; Austin, TX, USA) and Synthes Synfix (SynFix-LR; DePuy Synthes, West Chester, PA, USA). BMP2 transplant was used until January 2016 and bank bone graft BIOBANK (BIOBANK, Lieusaint, France) thereafter. A single type of disc arthroplasty, Synthes Prodisc-L (Prodisc-L, TDR, Zimmer Biomet), was used in this study.

\section{Statistical analysis}

Comparisons between data at the two time points, month 0 (M0) and month 12 (M12) were analyzed using the Student $t$-test (for matched data) and a chi-square test or Fisher exact test (for the discrete variables). Correlation between two quantitative variables was determined by Pearson's correlation. The results were expressed as mean \pm standard deviation and proportionally for continuous and discrete variables. Statistical analysis was performed with IBM SPSS Statistics ver. 20.0.0 for Mac OS X (IBM Corp., Armonk, NY, USA). All $p<0.05$ were considered statistically significant for all analyses (type 1 error), with a confidence interval (CI) of $95 \%$.

\section{Compliance with ethical standards}

All procedures performed in studies involving human participants were in accordance with the ethical standards of the institutional and/or national research committee and with the 1964 Helsinki declaration and its later amendments or comparable ethical standards. Informed consent was obtained from all individual participants included in the study. The study was approved by the local Research Ethics Boards (registration no., IRB 11/05-01) in January 2013.

\section{Results}

The patient disposition chart is shown in Fig. 3. Patient demographics are shown in Table 1.

\section{Clinical evaluation}

Prior to surgery, the mean VAS-scores for lower back pain was $7.6^{\circ} \pm 1.8^{\circ}$ (range, $3^{\circ}-10^{\circ}$ ), and ODI $46.8 \% \pm 13.4 \%$ (range, $10 \%-64^{\circ}$ ), which significantly reduced to $2.12^{\circ}$ (range, $0^{\circ}-6^{\circ}$ ) and $18.6 \% \pm 12.5 \%$ (range, $0 \%-40 \%$ ) at 12 months $(p<0.001)$ (Table 2$)$. There was no significant difference between G1 and G2 patient groups according to the preoperative lower back pain status and the ODI score before the surgery and even 12 months after.

\section{Analysis of lumbo-pelvic parameters}

1) Pelvic parameters

Pelvic parameters were not significantly modified between M0 and M12 (Table 3.). The mean SS angle was: $39.9^{\circ} \pm 7.0^{\circ}$ (range, $21.5^{\circ}-52.9^{\circ}$ ) at M0 and $40.8^{\circ} \pm 6.9^{\circ}$ (range, $\left.24.7^{\circ}-55.3^{\circ}\right)$ at M12 $(p=0.28)$. The variation in SS angle between G1 and G2 over M0 and M12 was not significantly different $\left(0.92^{\circ} \pm 4.2^{\circ}\right.$ and $0.81^{\circ} \pm 6.3^{\circ}$, respectively; $p=0.95$ ).

\section{2) Spinal parameters}

The L1-S1 GLL showed a significant increase from $57.3^{\circ} \pm 10.8^{\circ}$ (range, $33.5^{\circ}-88.3^{\circ}$ ) at M0 to $61.4^{\circ} \pm 12.6^{\circ}$ (range, $\left.35^{\circ}-91.7^{\circ}\right)$ at M12 $(p<0.001)$. The L4-S1 SL

Table 2. Clinical analysis: VAS low back pain and VAS leg pain

\begin{tabular}{lccc} 
& MO & M12 & $p$-value \\
VAS low back pain & $7.6 \pm 1.8$ & $2.2 \pm 1.4$ & $<0.001$ \\
VAS leg pain & $4.1 \pm 3.6$ & $2.2 \pm 2.9$ & $<0.001$ \\
ODI & $46.8 \% \pm 13.4 \%$ & $18.6 \% \pm 12.5 \%$ & $<0.001$ \\
\hline
\end{tabular}

Values are presented as mean \pm standard deviation. ODI determines the daily functionality of our patients. Evaluation was assessed preoperatively (M0) and at 12 months postoperatively (M12). VAS, Visual Analog Scale; ODI, Oswestry Disability Index. 
showed a significant increase from $35.1^{\circ} \pm 7.2^{\circ}$ (range, $11.9^{\circ}-51.13^{\circ}$ ) at $\mathrm{M} 0$ to $41.1^{\circ} \pm 6.7^{\circ}$ (range, $25.6^{\circ}-57.3^{\circ}$ ) after arthrodesis $(p<0.001)$. The L1-L4 (SL) showed a significant decrease from $22.5^{\circ} \pm 6.6^{\circ}$ (range, $9^{\circ}-37.17^{\circ}$ ) at M0 to $20.4^{\circ} \pm 8.5^{\circ}$ (range, $5.5^{\circ}-43.8^{\circ}$ ) at M12 ( $p=0.03$ ) was observed. No significant difference in TK was observed $(p=0.15)$ (Table 3). The variation in L4-S1 SL between G1 and G2 showed no significant difference $(p=0.57)$; however, a subgroup analysis showed same direction modification for SL (Tables 4, 5).

Table 3. Evolution of spino-pelvic parameters after an L5-S1 anterior lumbar interbody fusion procedure: average before surgery (M0) and at 12 months after surgery (M12)

\begin{tabular}{lccc} 
Variable & Mo & M12 & $p$-value \\
\hline Pelvic incidence $\left(^{\circ}\right)$ & $54.68 \pm 9.0(33.4$ to 77.5$)$ & $55.42 \pm 9.8(36.3$ to 73.6$)$ & 0.068 \\
\hline Sacral slope $\left(^{\circ}\right)$ & $39.9 \pm 7.0(21.5$ to 52.9$)$ & $40.8 \pm 6.9(24.7$ to 55.3$)$ & 0.28 \\
\hline Pelvic tilt $\left(^{\circ}\right)$ & $14.7 \pm 6.3(3.6$ to 25.9$)$ & $14.5 \pm 5.6(4.2$ to 26.2$)$ & 0.81 \\
\hline Thoracic kyphosis $\left(^{\circ}\right)$ & $48.53 \pm 13.9(9.5$ to 96.3$)$ & $34.3 \pm 12.0(31.0$ to 97.9$)$ & 0.15 \\
\hline C7 Barrey ratio $(\%)$ & $19.20 \pm 1.0(-421$ to 199$)$ & $2.2 \pm 1.7(-3.95$ to 219$)$ & 0.32 \\
\hline C7 sagittal lodge $\left(^{\circ}\right)$ & $3.2 \pm 2.5(-5.1$ to 10.6$)$ & $131.07 \pm 9.2(108.5$ to 147$)$ & 0.056 \\
\hline Spino-sacral angle $\left(^{\circ}\right)$ & $130.2 \pm 9.4(105.1$ to 148.1$)$ & $63.3 \pm 11.8(37.5$ to 88$)$ & 0.44 \\
\hline Sacral vertical axis $(\mathrm{mm})$ & $23.6 \pm 24.8(0$ to 100$)$ & $61.4 \pm 12.6(35$ to 91.7$)$ & $<0.001$ \\
\hline Cobb L1-S1 GLL $\left(^{\circ}\right)$ & $60.9 \pm 11.6(33.2$ to 86.2$)$ & $20.4 \pm 8.5(5.5$ to 43.8$)$ & $41.1 \pm 6.7(25.6$ to 57.3$)$
\end{tabular}

Values are presented as mean \pm standard deviation (min to max).

GLL, global lumbar lordosis; SL, segmental lordosis.

Table 4. Evolution of the spino-pelvic parameters after an isolated L5-S1 anterior lumbar interbody fusion procedure (group 1): average before surgery (M0) and at 12 months after surgery (M12)

\begin{tabular}{|c|c|c|c|}
\hline Variable & MO & M12 & $p$-value \\
\hline Pelvic incidence $\left({ }^{\circ}\right)$ & $53.8 \pm 8.3$ (33.4 to 71.8 ) & $55.03 \pm 8.2$ (40 to 71.8 ) & 0.02 \\
\hline Sacral slope $\left({ }^{\circ}\right)$ & $39.5 \pm 6.7$ (22.6 to 52.3 ) & $40.2 \pm 5.9$ (28.0 to 50$)$ & 0.42 \\
\hline Pelvic tilt $\left({ }^{\circ}\right)$ & $14.2 \pm 6.1$ (3.6 to 23.6 ) & $14.7 \pm 5.4$ (5 to 26.2 ) & 0.53 \\
\hline Thoracic kyphosis $\left({ }^{\circ}\right)$ & $48.8 \pm 16.3$ (9.5 to 96.3) & $52.4 \pm 11.9$ (40.8 to 97.9$)$ & 0.14 \\
\hline C7 Barrey ratio (\%) & $30.8 \pm 1.16(-421$ to 199$)$ & $40.1 \pm 6.7$ (-95 to 219) & 0.66 \\
\hline C7 sagittal lodge $\left(^{\circ}\right)$ & $3.5 \pm 2.9(0.3$ to 10.6$)$ & $1.9 \pm 1.5(0.04$ to 4.9$)$ & 0.02 \\
\hline Spino-sacral angle $\left({ }^{\circ}\right)$ & $129.3 \pm 9.0$ (105.1 to 144.8$)$ & $130.3 \pm 6.6$ (117.8 to 141$)$ & 0.37 \\
\hline Sacral vertical axis (mm) & $27.9 \pm 27.3(0$ to 100$)$ & $13.7 \pm 11.0(0$ to 41$)$ & 0.01 \\
\hline Cobb L1-S1 GLL $\left(^{\circ}\right)$ & $60.4 \pm 12.7$ (33.2 to 86.2) & $63.8 \pm 11.2$ (49.8 to 88 ) & 0.81 \\
\hline L1-S1 GLL $\left(^{\circ}\right)$ & $57.8 \pm 11.9$ (32.5 to 88.3) & $62 \pm 12.7$ (43 to 91.7 ) & 0.001 \\
\hline L1-L4 SL ( $\left.{ }^{\circ}\right)$ & $22.8 \pm 7$ (9 to 37.1$)$ & $20.5 \pm 8.4$ (5.5 to 43.8) & 0.056 \\
\hline L4-S1 SL $\left({ }^{\circ}\right)$ & $35.1 \pm 7.9(11.9$ to 51.1$)$ & $41.6 \pm 6.5$ (30 to 57.3 ) & $<0.001$ \\
\hline L5-S1 SL $\left(^{\circ}\right)$ & $20.3 \pm 6.4$ (11.4 to 35$)$ & $26.7 \pm 5.9$ (16.5 to 41.7) & $<0.001$ \\
\hline L4-L5 SL $\left({ }^{\circ}\right)$ & $24.9 \pm 5.9$ (8.5 to 36$)$ & $27.6 \pm 7.2(17$ to 46.3$)$ & 0.06 \\
\hline
\end{tabular}

Values are presented as mean \pm standard deviation (min to max).

GLL, global lumbar lordosis; SL, segmental lordosis. 
3) Sagittal balance parameters

According to Roussouly's classification, $13 \%$ of the patients presented a type 1 or 2 with low SS values and no change at M12. Type 3 patients formed $70 \%$ of the total prior to surgery, which reduced, albeit non-significantly, to $58 \%$ after surgery $(p=0.22)$ (Table 6 ).

Sagittal balance analysis showed no significant modification of SSA; $130.2^{\circ} \pm 9.4^{\circ}$ (range, $105^{\circ}-148.1^{\circ}$ ) at $\mathrm{M} 0$ and $131.07^{\circ} \pm 9.2^{\circ}$ (range, $\left.108.5^{\circ}-147^{\circ}\right)$ after surgery $(p=0.44$ ). A significant decrease in SVA after surgery was observed; from $23.6 \pm 24.8 \mathrm{~mm}$ (range, $0-100 \mathrm{~mm}$ ) at M0 to $14.9 \pm 13.3 \mathrm{~mm}$ (range, $0-43 \mathrm{~mm}$ ) at M12 ( $p<0.001)$. Subgroup analysis showed no significant difference in SVA between G1 and G2. Further, there was no significant correlation of SVA and variation of SS $(p=0.16)$ and between variations of SS and SVA $(p=0.26)$
Unbalanced patients comprised $27 \%$ of the total at M0 and $11 \%$ at M12 ( $p=0.07)$ (Table 7$)$. Of the four patients with a sagittal balanced spine (73\%) prior to surgery, $44 \%$ had abnormal kinematics parameters and only $17 \%$ after arthrodesis $(p<0.01)$. No correlation was found between variation in clinical and radiological parameters (Table 8).

\section{Discussion}

The ALIF procedure for the arthrodesis of the lumbosacral level generated satisfactory clinical and radiological results [17]. The impact of isolated lumbosacral fusion by ALIF procedure on SL L5-S1 and its influence on the other spino-pelvic parameters, especially considering variation of the pelvic parameters, the GLL and SLL and the association with types of spine and kinematics parameters.

Table 5. Evolution of the spino-pelvic parameters after hybrid surgery (group 2): average before surgery (M0) and at 12 months after surgery (M12); comparison of variation between two groups

\begin{tabular}{|c|c|c|c|c|c|c|}
\hline Variable & MO & M12 & $p$-value & $\begin{array}{c}\text { Group } 1 \\
\text { (M12-M0) }\end{array}$ & $\begin{array}{c}\text { Group } 2 \\
\text { (M12-M0) }\end{array}$ & $p$-value \\
\hline Pelvic incidence $\left({ }^{\circ}\right)$ & $56.5 \pm 10.5$ (38.2 to 77.5$)$ & $56.2 \pm 10.6$ (36.3 to 73.6$)$ & 0.64 & & & \\
\hline Sacral slope $\left({ }^{\circ}\right)$ & $40.9 \pm 7.9(21.5$ to 52.9$)$ & $41.7 \pm 7.8$ (24.7 to 55.3$)$ & 0.66 & $0.92 \pm 4.2$ & $0.81 \pm 6.3$ & 0.95 \\
\hline Pelvic tilt $\left({ }^{\circ}\right)$ & $15.5 \pm 6.9$ (4.6 to 25.9$)$ & $14.4 \pm 5.9(4.2$ to 25$)$ & 0.55 & & & \\
\hline Thoracic kyphosis ( $\left.{ }^{\circ}\right)$ & $47.7 \pm 6.2(37.9$ to 60$)$ & $48.7 \pm 12.5$ (31 to 74.2 ) & 0.76 & & & \\
\hline C7 Barrey ratio (\%) & $-4.5 \pm 7(-209$ to 110$)$ & $256 \pm 8$ (-81 to 182) & 0.18 & & & \\
\hline C7 sagittal lodge $\left({ }^{\circ}\right)$ & $1.5 \pm 2.4(-5.1$ to 3$)$ & $3.2 \pm 1.3(0.8$ to 4.7$)$ & 0.08 & & & \\
\hline Spino-sacral angle $\left({ }^{\circ}\right)$ & $132.3 \pm 10(107.2$ to 148.1$)$ & $131.7 \pm 10.6$ (108.5 to 144.7$)$ & 0.84 & & & \\
\hline Sacral vertical axis (mm) & $14.3 \pm 15.2$ (0 to 52) & $17.4 \pm 17.5(-2$ to 43$)$ & 0.49 & & & \\
\hline Cobb L1-S1 GLL $\left(^{\circ}\right)$ & $62.2 \pm 9.3$ (40.9 to 77$)$ & $62.1 \pm 13.5$ (37.5 to 83.2) & 0.96 & & & \\
\hline L1-S1 GLL $\left(^{\circ}\right)$ & $56.9 \pm 8.5$ (36 to 70.5$)$ & $60.2 \pm 13$ (35 to 76.9$)$ & 0.19 & $4.1 \pm 5.6$ & $3.3 \pm 8.3$ & 0.74 \\
\hline L1-L4 SL $\left(^{\circ}\right)$ & $21.8 \pm 6.1$ (12 to 30.9$)$ & $20.1 \pm 9.1$ (6.5 to 39.8) & 0.35 & & & \\
\hline L4-S1 SL $\left(^{\circ}\right)$ & $35 \pm 5.7(24$ to 41.4$)$ & $40.1 \pm 7.1$ (25.6 to 49.5$)$ & 0.041 & $6.4 \pm 5.7$ & $5.05 \pm 7.5$ & 0.57 \\
\hline L5-S1 SL $\left(^{\circ}\right)$ & $19 \pm 4.7$ (10.7 to 26.7) & $204 \pm 6.0(10.7$ to 28.9$)$ & 0.42 & & & \\
\hline L4-L5 SL ( $\left.{ }^{\circ}\right)$ & $26.1 \pm 4.0$ (18.5 to 33$)$ & $29.9 \pm 7.1$ (12.3 to 37.6$)$ & 0.15 & & & \\
\hline
\end{tabular}

Values are presented as mean \pm standard deviation (min to max).

GLL, global lumbar lordosis; SL, segmental lordosis.

Table 6. Comparison of spine type before surgery (M0) and at 12 months after surgery (M12)

\begin{tabular}{lcccccc} 
Spine type (Roussouly classification) & Mo & M12 & $p$-value & Group 1 at Mo & Group 2 at M0 & $p$-value \\
Type 1 or $2:$ SS $<35^{\circ}$ & $5(13)$ & $8(21)$ & 0.35 & $3(12)$ & $2(16)$ & 0.69 \\
Type 3: $35^{\circ}<S S<45^{\circ}$ & $26(70)$ & $21(58)$ & 0.22 & $17(68)$ & $8(66)$ & 0.93 \\
Type 4: $S S>45^{\circ}$ & $6(17)$ & $8(2)$ & 0.55 & $5(20)$ & $2(16)$ & 0.80 \\
\hline
\end{tabular}

Values are presented as number (\%).

SS, sacral slope. 
Table 7. Categorization according to sagittal balance parameters: comparison before surgery (M0) and at 12 months after surgery (M12)

\begin{tabular}{|c|c|c|c|c|c|c|}
\hline Variable & MO & M12 & $p$-value & Group 1 at MO & Group 2 at MO & $p$-value \\
\hline \multicolumn{7}{|l|}{ Sagittal unbalance criteria } \\
\hline C7 Barrey ratio $>100 \%$ or $<-100 \%$ & $10(27)$ & $4(11)$ & 0.13 & $8(32)$ & $2(16)$ & 0.44 \\
\hline Sacral vertical axis $>50 \mathrm{~mm}$ & $6(17)$ & 0 & 0.02 & $5(20)$ & $1(8)$ & 0.64 \\
\hline \multicolumn{7}{|l|}{ Compensatory mechanism criteria } \\
\hline Pelvic tilt $>20^{\circ}$ & $7(19)$ & $6(17)$ & 0.76 & & & \\
\hline Thoracic kyphosis $<30^{\circ}$ & $3(8)$ & 0 & 0.23 & & & \\
\hline Globally unbalanced & $10(27)$ & $4(11)$ & 0.07 & $8(32)$ & $2(16)$ & 0.44 \\
\hline Globally balanced with compensatory mechanism & $6(17)$ & $6(17)$ & 1 & & & \\
\hline
\end{tabular}

Values are presented as number (\%).

Table 8. Correlation between variation of clinical and radiological parameters at M0 and M12

\begin{tabular}{|c|c|c|c|c|c|c|}
\hline \multirow{2}{*}{ Mo-M12 } & \multicolumn{2}{|c|}{ VAS low back pain } & \multicolumn{2}{|c|}{ VAS leg pain } & \multicolumn{2}{|c|}{ Oswestry Disability Index } \\
\hline & $r$ & $p$-value & $r$ & $p$-value & $r$ & $p$-value \\
\hline L1-S1 global lumbar lordosis $\left({ }^{\circ}\right)$ & 0.90 & 0.37 & 2.05 & 0.04 & 0.16 & 0.87 \\
\hline L4-S1 segmental lordosis $\left({ }^{\circ}\right)$ & 1.0 & 0.30 & 0.80 & 0.43 & 0.26 & 0.79 \\
\hline Sacral vertical axis (mm) & 0.24 & 0.81 & 2.2 & 0.03 & 0.95 & 0.35 \\
\hline
\end{tabular}

VAS, Visual Analog Scale.

Among pelvic parameters in the literature, no significant change was observed considering the postoperative variation of the SS $[18,19]$. We hypothesized that isolated ALIF procedure, regardless of its association with L4L5 LDR, can modify GLL and SLL values of the lumbar spine. Accordingly, we observed a significant increase in L5-S1 SL $\left(19.9^{\circ} \pm 5.9^{\circ}\right)$ versus after arthrodesis $\left(24.7^{\circ} \pm 6.6^{\circ}\right)$ $(p<0.001)$ and change of GLL. Considering the SL and the influence of the loss of height of the intervertebral disc in case of discopathy on the lower and upper part of the lumbar spine, decrease of distal LL with a slight variation of the proximal LL was noted, in concordance with findings reported by others $[1,2]$. After L5-S1 arthrodesis, proximal LLS (L1-L4 SL) decreased $(p=0.03)$ and distal LLS (L4-S1 SL) significantly increased $(p<0.001)$. Afathi et al. [18] reported a similar change with increased L4S1 SL $(p=0.0013)$, but decreased in the proximal part but without significant difference in global lordosis.

Concerning sagittal balance, most studies analyzing the modification of the lumbo pelvic complex were conducted on balanced patient $[18,20]$. However, distal lumbar degenerative disc disease (L4-S1 level) could be associated with sagittal unbalanced criteria [5] (Fig. 4). After ALIF procedure, we observed a significant improvement in the

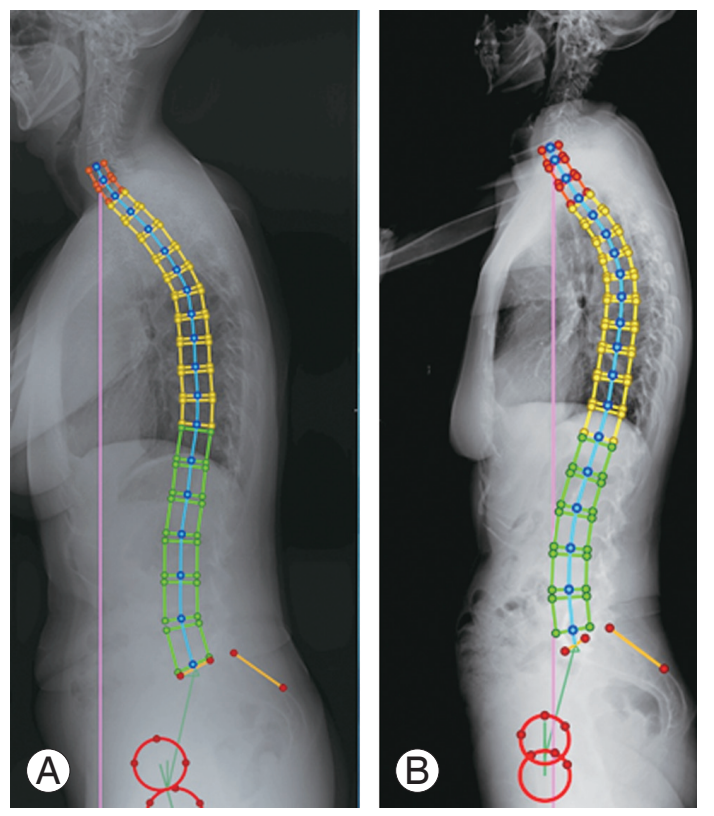

Fig. 4. Illustrative case: (A) preoperative full-spine standing X-ray, patient of 58 years old with isolated low back pain with criteria of sagittal imbalance (sacral vertical axis distance greater than $50 \mathrm{~mm}$ or C7 Barrey ratio $>100 \%$ ). (B) Postoperative full-spine at 12 months, increase of segmental lordosis L4-S1 and restitution of sagittal balance.

sagittal balance and the kinematics parameters. While $27 \%$ of the patients were unbalanced before the surgery, 
only $11 \%$ were unbalanced after the surgery. No significant variation of the SS as the SSA was associated to this restoration, in concordance with the lack of variation reported by others [16]. They had shown improvement of the sagittal balance in unbalanced preoperative population of patient after L5-S1 TDR, in particular in case of unbalanced patients with low SS values (Roussouly type 1 and 2). In the case of TDR, patients with a high SS presented increased shear stresses and had reduced capacity to regulate its lumbo-pelvic complex. The authors of that study concluded that fusion was a more appropriate solution for these patients (Roussouly type 3 and 4) and that insertion of an intersomatic cage even with lordosis did not restore lordosis contrary to disc arthroplasty, but only the disc height. We noted in our study that that $95 \%$ of patients had PI greater than $40^{\circ}$ and $87 \%$ with a SS greater than $35^{\circ}$ (Roussouly type 3 and 4 ). Criteria for TDR on L4-L5 level were L5-S1 discopathy with low PI or low need for SS increase without arthritis (criteria were verified by full spine X-ray, CT-scan, and MRI).

We found an increase in the distal part of the LL and the variation can explain this improvement and the significant decrease of the SVA [1]. Likewise, the variation of the distal LL can partly explain the amendment of Roussouly's type especially for the type 3 after the surgery. Restitution of global sagittal alignment is provided by an increase in the high and SL of L4-S1 level. Change in SS and LL seems to be superior on unbalanced patient, but the correlation with SVA was not significant.

Variations of kinematics parameters were observed in patient with low back pain without disc diseases or objective pathology of the spine $[1,21]$. Pain and or pseudarthrosis can influence spino-pelvic parameters. All the patients presented a significant pain relief after surgery and were all fused considering Lenke's classification and criteria of Surgical Interbody Research Group [10]. Pain relief can be a factor to consider in those variations.

This study is not without its limitations. We found significant variation of PI in $\mathrm{G} 1\left(1.2^{\circ}, p=0.002\right)$, while this parameter was described as invariable [22]. This variation can be explained by the lack of accuracy of the collected data regarding the conventional limits of the X-ray measurement. The placement of the point on the software with various qualities of the full-spine $\mathrm{X}$ ray was perhaps more relevant than the sacro-iliac joints modifications described as a cause of variation of the PI [23]. In this context, EOS system would have been more reliable [24,25].
The sample size was small and patient heterogeneity, particularly regarding hybrid surgery can be debatable. However no significant difference was observed between the two groups according to the clinical or radiological data before or after the surgery, and thus the two groups may be considered to be similar.

Use of Roussouly's classification for the sagittal morphotype did not consider in the type 3 subgroup of patient with anteverted pelvis as described in the recent classification [11], which can partly explain the variations between pre- and postoperative assessments. However our study focused on the specific analysis of the modifications of the segmental LL particularly in unbalanced patient or patients balanced with abnormal kinematics parameters, and significant variations of the distal arch of the LL mainly in the unbalanced population were observed.

\section{Conclusions}

Isolated surgery on distal lumbar segment (L4-S1 level) by anterior approach allows the restitution of lumbosacral SL, and modification of the segmental and GLL. Restitution of the lumbosacral height allows improvement of sagittal balance and kinematics parameters.

\section{Conflict of Interest}

No potential conflict of interest relevant to this article was reported.

\section{ORCID}

Stanislas Marouby: https://orcid.org/0000-0003-1388-918X Remy Coulomb: https://orcid.org/0000-0002-7967-9356 Etienne Maury: https://orcid.org/0000-0001-6497-6879 Olivier Mares: https://orcid.org/0000-0001-8476-4347

\section{References}

1. Barrey C, Roussouly P, Le Huec JC, D’Acunzi G, Perrin G. Compensatory mechanisms contributing to keep the sagittal balance of the spine. Eur Spine J 2013;22 Suppl 6:S834-41.

2. Barrey C, Jund J, Noseda O, Roussouly P. Sagittal balance of the pelvis-spine complex and lumbar degenerative diseases: a comparative study about 85 cases. Eur Spine J 2007;16:1459-67. 
3. Berthonnaud E, Dimnet J, Roussouly P, Labelle H. Analysis of the sagittal balance of the spine and pelvis using shape and orientation parameters. J Spinal Disord Tech 2005;18:40-7.

4. Janik TJ, Harrison DD, Cailliet R, Troyanovich SJ, Harrison DE. Can the sagittal lumbar curvature be closely approximated by an ellipse? J Orthop Res 1998;16:766-70.

5. Esposito CI, Miller TT, Kim HJ, et al. Does degenerative lumbar spine disease influence femoroacetabular flexion in patients undergoing total hip arthroplasty? Clin Orthop Relat Res 2016;474:1788-97.

6. Lazennec JY, Clark IC, Folinais D, Tahar IN, Pour AE. What is the impact of a spinal fusion on acetabular implant orientation in functional standing and sitting positions? J Arthroplasty 2017;32:3184-90.

7. Haldeman S, Johnson CD, Chou R, et al. The Global Spine Care Initiative: classification system for spinerelated concerns. Eur Spine J 2018;27(Suppl 6):889900.

8. Urrutia J, Besa P, Campos M, et al. The Pfirrmann classification of lumbar intervertebral disc degeneration: an independent inter- and intra-observer agreement assessment. Eur Spine J 2016;25:2728-33.

9. Bridwell KH, Lenke LG, McEnery KW, Baldus C, Blanke K. Anterior fresh frozen structural allografts in the thoracic and lumbar spine: do they work if combined with posterior fusion and instrumentation in adult patients with kyphosis or anterior column defects? Spine (Phila Pa 1976) 1995;20:1410-8.

10. Burkus JK, Foley K, Haid RW, LeHuec JC. Surgical Interbody Research Group: radiographic assessment of interbody fusion devices: fusion criteria for anterior lumbar interbody surgery. Neurosurg Focus 2001;10:E11.

11. Laouissat F, Sebaaly A, Gehrchen M, Roussouly P. Classification of normal sagittal spine alignment: refounding the Roussouly classification. Eur Spine J 2018;27:2002-11.

12. Roussouly P, Gollogly S, Berthonnaud E, Dimnet J. Classification of the normal variation in the sagittal alignment of the human lumbar spine and pelvis in the standing position. Spine (Phila Pa 1976) 2005;30:346-53.

13. Savage JW, Patel AA. Fixed sagittal plane imbalance. Global Spine J 2014;4:287-96.

14. Schwab F, Lafage V, Patel A, Farcy JP. Sagittal plane considerations and the pelvis in the adult patient. Spine (Phila Pa 1976) 2009;34:1828-33.

15. Schwab F, Ungar B, Blondel B, et al. Scoliosis Research Society-Schwab adult spinal deformity classification: a validation study. Spine (Phila Pa 1976) 2012;37:1077-82.

16. Rivière C, Lazennec JY, Van Der Straeten C, Auvinet E, Cobb J, Muirhead-Allwood S. The influence of spinehip relations on total hip replacement: a systematic review. Orthop Traumatol Surg Res 2017;103:559-68.

17. Pinson H, Hallaert G, Herregodts P, et al. Outcome of anterior lumbar interbody fusion: a retrospective study of clinical and radiologic parameters. World Neurosurg 2017;103:772-9.

18. Afathi M, Zairi F, Devos P, et al. Anterior lumbar sagittal alignment after anterior or lateral interbody fusion. Orthop Traumatol Surg Res 2017;103:1245-50.

19. Pellet N, Aunoble S, Meyrat R, Rigal J, Le Huec JC. Sagittal balance parameters influence indications for lumbar disc arthroplasty or ALIF. Eur Spine J 2011;20 Suppl 5:647-62.

20. Le Huec J, Basso Y, Mathews H, et al. The effect of single-level, total disc arthroplasty on sagittal balance parameters: a prospective study. Eur Spine J 2005;14:480-6.

21. Lazennec JY, Ramare S, Arafati N, et al. Sagittal alignment in lumbosacral fusion: relations between radiological parameters and pain. Eur Spine J 2000;9:47-55.

22. Legaye J, Duval-Beaupere G, Hecquet J, Marty C. Pelvic incidence: a fundamental pelvic parameter for three-dimensional regulation of spinal sagittal curves. Eur Spine J 1998;7:99-103.

23. Lee JH, Na KH, Kim JH, Jeong HY, Chang DG. Is pelvic incidence a constant, as everyone knows?: changes of pelvic incidence in surgically corrected adult sagittal deformity. Eur Spine J 2016;25:3707-14.

24. Lazennec JY, Rousseau MA, Rangel A, et al. Pelvis and total hip arthroplasty acetabular component orientations in sitting and standing positions: measurements reproductibility with EOS imaging system versus conventional radiographies. Orthop Traumatol Surg Res 2011;97:373-80.

25. Maillot C, Ferrero E, Fort D, Heyberger C, Le Huec JC. Reproducibility and repeatability of a new computerized software for sagittal spinopelvic and scoliosis curvature radiologic measurements: Keops(R). Eur Spine J 2015;24:1574-81. 